\title{
Applying of a design methodology for a new mobility product
}

\author{
Vlad Gheorghiță and Cătălin Gheorghiță
}

Politehnica University of Bucharest, Department of Manufacturing Technology, Splaiul Independetei, No. 313, 060042, Bucharest, Romania

\begin{abstract}
Product innovation involves an understanding of technology through the introduction of a product that is new or has significantly improved characteristics and intended uses with the purpose of upgrading or even changing, in this case, the mobility landscape. Although product development is creative in upgrading components, the implementation requires a systematic approach to guide the processes that must be taken into account and applied to achieve the implementation of a new product to market. To be successful it is important that the needs, preferences and limitations, be taken into consideration. In this paper, an optimized methodology for developing a new product is proposed starting from the existing ones. By investigating the current concepts of solutions to improve the ability to move physically, it is attempted to propose a typology to address the mobility problem. On a basic manual wheelchair, a system will be attached to ensure overcoming the obstacles and to guarantee the ability to negociate effectively.
\end{abstract}

\section{Introduction}

The wheelchair has become today indispensable for people experiencing various locomotor disabilities. Fortunately, technological progress has managed to significantly improve the life of people with mobility issues, giving them freedom of movement increasingly higher. The widespread use of various types of wheelchairs is currently known including holding eye-level discussions with people by balancing on two wheels, going up and down steep ramps, traversing outdoor surfaces, climbing curbs and stairs. However, there are still limitations for indoor purposes due to small and confined spaces. There are many studies conducted in areas related to climbing mechanisms and hence, a number of stair climbing mechanisms have been developed for wheelchairs.

Quaglia [1] analyzed aspects of developing a wheelchair for climbing stairs, which can move in various environments that can go over obstacles. The framework consists of a chassis built with two motorized units, support for two electric motors, two wheels and a battery triple. The seat has a tubular structure consisting of a frame and a pivoting wheel. Linkage mechanism is responsible for the relative movement between the frame and the seat during operation and is driven by a motor connected to a lead screw mechanism.

\footnotetext{
*Corresponding author: vlad.gheorghita@upb.ro
} 
Lawn [2] proposed a mechanism that is based on the use of four wheels, where the rear wheels are driven independently and the front wheels are free wheel. Also the influence of external factors was evaluated by analyzing the recent advances in mobility assistive devices available for obstacles.

Yuan and Hirose [3] proposed a product with two pairs of parallel wheels that are used to perform stair-climbing motion, with the tire diameter smaller compared to the step height.

Suryawanshi [4] proposes a conceptual design of a transfer mechanism in a wheelchair that assists the disabled person to move easily onto the bed and back again.

Yoneda [5] proposed a deformable track considering the fundamental track based problem, respectively that of the high pressure exerted on the stair edges. The vehicle can easily climb stairs by using two active arms positioned front. A wheelchair with pure leg locomotion has a high climbing capability, but it requires a complex structure for both the control and actuation systems [6].

The stability is a critical aspect when a mobility product is developed, and in this case the seat oscillates due to leg movement during both stair-climbing and flat ground motion, thus causing an unpleasant sensation for the user.

\section{Design process}

A design process applies to systems, assemblies and components and is used for new or innovative products and for making changes to existing products. Even if a product is developed or just modified, there are stages that need to be covered for all projects $[7,8]$.

Wheelchair users are confronted with the problem of limited mobility because the design of wheelchairs is not sufficiently addressed by changing the use environments.

Ease of handling is essential for the users with mobility issues, disabled or elderly and will be the important point for acceptability.

The aspect of maximizing autonomy will be a motivation behind this mechanism, which reduces the need to rely on external assistance or special equipment.

The next goal is to achieve a mechanism that does not exceed the physical dimensions of the existing technology. This is achieved in a basic design, but some dimensions of the prototype may be due to the use of mechanical components that are not available on an appropriate scale.

Other objective is a design based on the use of relatively low components. The aspect of maximizing the operating range is inherently related to the weight of the equipment, and the addition of functionality, increasing the charging of the power supply which also reduces the operating range compared to a standard motor.

\section{Design methodology}

In engineering design, all products have some rightful reason behind their existence: the product functions $[9,10]$. A very important early stage in the design process is the conceptual design stage, during which an initial design solution to the design problem is devised to fulfill the required functions [9].

A technical system can be originally modeled as a "black box" with inputs of energy, material, signal and system outputs. The technical system therefore presupposes a functional relationship between inputs and outputs and the black box is the wheelchair's overall function, shown in the following Figure 1. 


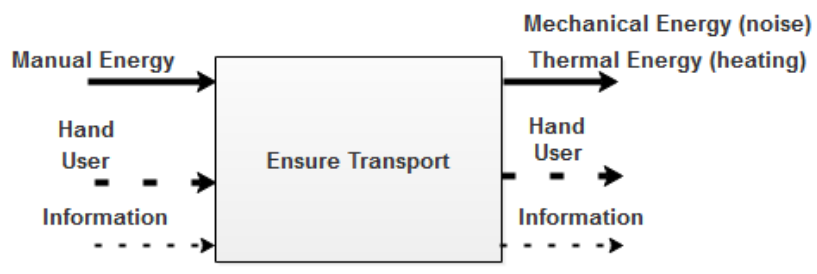

Fig. 1. Black box of the product.

Using physical decomposition as in Figure 2, the product can be decomposed into subassemblies, components, and then the product structure is developed.

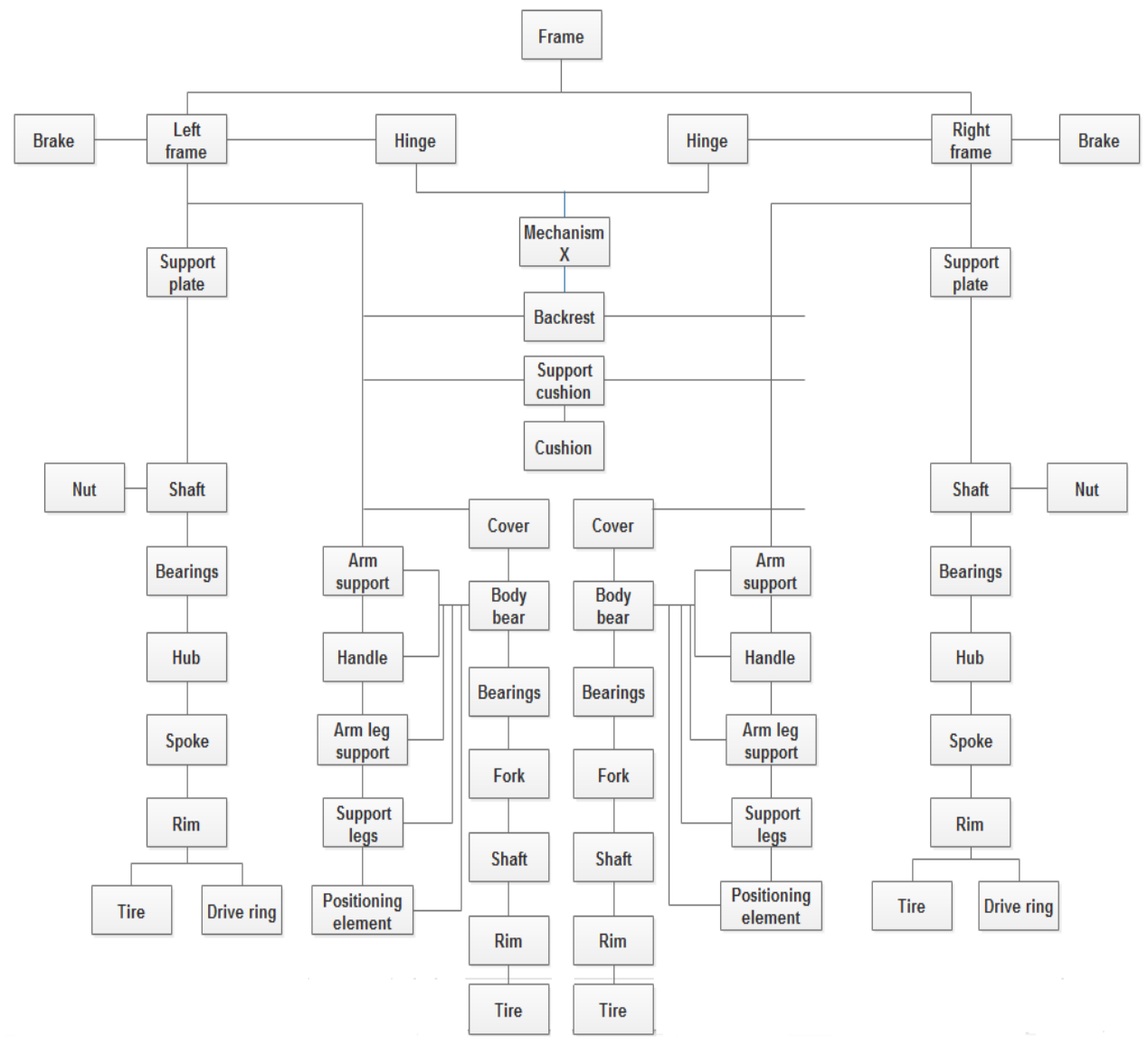

Fig. 2. Physical decomposition of the wheelchair.

Functional decomposition finds critical product features and attributes that describe functions with input and output flows defined as material, information, and energy.

The structured method for decomposing the functions of a product is hierarchized as follows and presented in the following Table 1, [11]: identifies the components of the product and their functions; describes the interaction between component functions; clarifies the best solution to meet the customer's need by describing the function of the product or component, uses functional descriptions for generating and selecting sets of technology components that meet basic functional requirements. 
Table 1. Analysis of component - function.

\begin{tabular}{|c|c|c|c|}
\hline Nr. & Component & Function & Observation \\
\hline 1. & Push handle & Allows a back-up aid to the seat & $\begin{array}{l}\text { Extension of the top of the } \\
\text { frame }\end{array}$ \\
\hline 2. & Back of the back & Supports the user's back & $\begin{array}{l}\text { Suspension between the vertical } \\
\text { components of the seat }\end{array}$ \\
\hline 3. & Support arms & Supports the arms & $\begin{array}{l}\text { They can be rotated during the } \\
\text { transfer without having to be } \\
\text { removed }\end{array}$ \\
\hline 4. & Wheel rim & Ensures the surface on which the tire is mounted & $\begin{array}{l}\text { It is connected to the spindle } \\
\text { through the spoke }\end{array}$ \\
\hline 5. & Spokes & Connect the tire and the rim to the axle & $\begin{array}{c}\text { Represents the suspension } \\
\text { system }\end{array}$ \\
\hline 6. & Hub & Connect spoke and rim & $\begin{array}{l}\text { The central component of the } \\
\text { wheel }\end{array}$ \\
\hline 7. & Unlocking Axis & $\begin{array}{l}\text { Allows the wheel to disconnect quickly and easily } \\
\text { from the frame }\end{array}$ & - \\
\hline 8. & Plate & Connect the wheel to the frame via the spindle & $\begin{array}{l}\text { It is adjustable and allows to } \\
\text { extend the wheel base }\end{array}$ \\
\hline 9. & Seat frame & Supports seat and wheels & $\begin{array}{l}\text { Increases the stability of the } \\
\text { wheelchair or reduces travel } \\
\text { time }\end{array}$ \\
\hline 10. & Brakes & $\begin{array}{c}\text { Allow the wheels to be locked, preventing } \\
\text { unwanted movement }\end{array}$ & Rigid and tubular structure \\
\hline 11. & Framework & - & $\begin{array}{l}\text { Extends from frame to wheel } \\
\text { and uses a locking system }\end{array}$ \\
\hline 12. & Lock lever & Ensures the legs during transfer & \\
\hline 13. & Cover of the casing & Protects the bearings & $\begin{array}{l}\text { It is located so that it is easily } \\
\text { accessible }\end{array}$ \\
\hline 14. & Casting plate & Connect the tubular casing to the tubular frame & $\begin{array}{l}\text { Allows lubrication of bearings } \\
\text { inside the casing }\end{array}$ \\
\hline 15. & Housing & Increases the maneuverability of the seat & - \\
\hline 16. & Cushion & $\begin{array}{l}\text { Allows the dispersion and absorption of the force } \\
\text { between the user's body and the settlement surface }\end{array}$ & $\begin{array}{c}\text { Fixed on a tubular extension of } \\
\text { the frame }\end{array}$ \\
\hline 17. & Pillow holder & Allows the seat to gather & $\begin{array}{c}\text { It contains ball bearings and } \\
\text { forms a swivel joint that can } \\
\text { rotate } 360 \text { degrees }\end{array}$ \\
\hline 18. & Hinge $\mathrm{X}$ & $\begin{array}{l}\text { Ensures expansion from the frame to the cross } \\
\text { members of a foldable frame }\end{array}$ & - \\
\hline
\end{tabular}

Decomposition of the problem allows finding technical solutions for complex design problems by taking into account simpler subproblems. Design can focus on critical subproblems, others are postponed. The main function of the wheelchair, to transport the user, was divided into five primary subfunctions: facilitates movement, ensures energy, supports user, changes direction, provides support. These functions were then further divided until the description was detailed enough to describe a specific mechanism as shown in Figure 3.

\begin{tabular}{|c|c|c|c|c|c|c|}
\hline & 1 & 2 & 3 & 4 & 5 & 6 \\
\hline $\begin{array}{c}\text { Transmission of } \\
\text { power }\end{array}$ & DC curent Motor & Stepper Motor & Hydraulic Motor & $\begin{array}{c}\text { Pneumatic } \\
\text { Motor } \\
\end{array}$ & Manual & \\
\hline $\begin{array}{l}\text { Source of } \\
\text { energy }\end{array}$ & $\begin{array}{l}\downarrow \mathrm{NiCd} \text { (Nichel- } \\
\text { Cadmium) }\end{array}$ & $\begin{array}{l}\text { NiMh (Nichel- } \\
\text { Metal-Hydrid) }\end{array}$ & - $\mathrm{LiCoO}_{2}$ & $\mathrm{LiNiMnCoO}_{2}$ & anual Force & \\
\hline $\begin{array}{c}\text { Torque } \\
\text { transmission }\end{array}$ & Conical gears & Differential & rical ge & Worm gear & 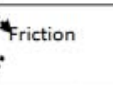 & Manual \\
\hline Control System & Buttons & Joystick & $\mathrm{cal}$ & Touch & Manual & \\
\hline Brake System & On disk & On the dr & Tire & & & \\
\hline $\begin{array}{l}\text { Direction } \\
\text { Control }\end{array}$ & $\begin{array}{l}\text { With additionals } \\
\downarrow \text { engine }\end{array}$ & & alvohet & & & \\
\hline $\begin{array}{l}\text { Placement of } \\
\text { Action Source }\end{array}$ & In the hub & $\begin{array}{c}\text { On the back of } \\
\text { the seat }\end{array}$ & On the seat axis & "Btehind the seat & & \\
\hline
\end{tabular}

Fig. 3. Morphological Chart of the system.

Once the morphological chart has been developed, it is possible to combine individual solutions into effective conceptual projects [12]. This methodology is not a substitute for 
creative thinking, but a structured means for developing and documenting design alternatives. The concept selection process is done using the Pugh method [11, 13] where the concepts were narrow down first by concept screening and then by concept scoring. After the best concept is selected, the detailed design and specifications will be defined. The highest score involves the use of the following components, $\mathrm{DC}$ motor, $\mathrm{LiCoO}_{2}$ battery, worm gear, joystick, additional steering control behind the seat, normal wheels, has been adopted.

The functions from the last branch of the diagram were then incorporated into a morphological chart used to brainstorm possible corresponding mechanisms. The morphological chart is organized according to the results of the FAST diagram and was used to generate complete concepts as shown in Figure 4.

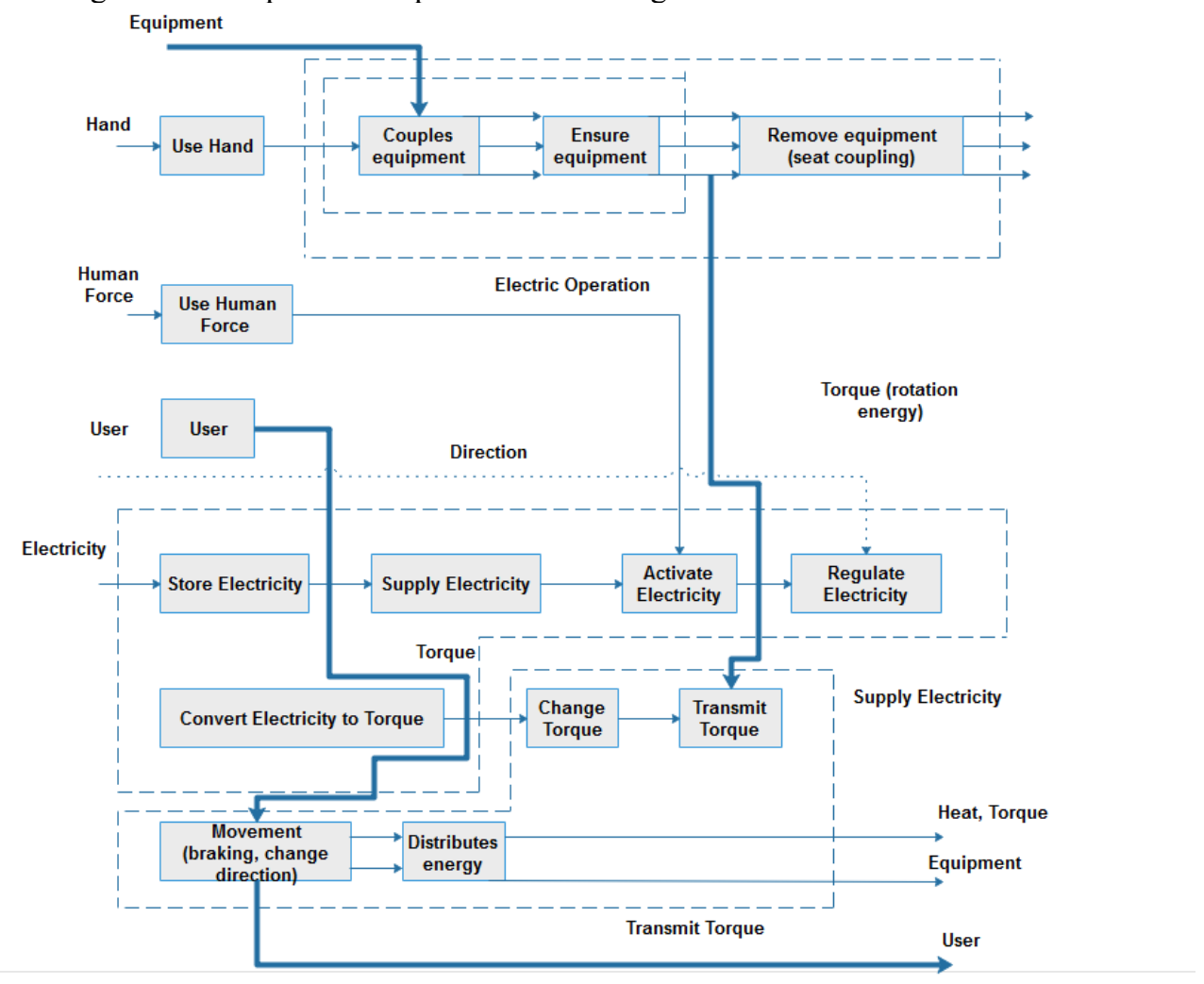

Fig. 4. Functional Analysis System Technique.

After determining the required functions, methods were brainstormed that could be used to perform each. The functions which primarily describes the structural components of the chair, resulted in numerous solutions. To generate a complete design, one concept from each subfunction category was selected.

\section{Conclusions}

The methodologies used in product development are set to evolve with the maturity in process model. In a methodology for developing a new product, it is essential to have a design procedure where all the activities and stages must be crossed with the purpose to find the best solutions. To ensure the developing of better products, structured and more agile methodologies are needed because of the accelerating appearance of new technologies 
and the change and increase of customer demands that create a faster moving framework of product development.

The proposed approach towards an adaptive methodology allows a more dynamic and detailed adaptation to the development context. To allow this break down of the product development methodology, the product is decomposed into modules. The new attachment system proposed will be designed to provide the possibility for a wheelchair user to have a cheap product without permanently altering the existing product, will provide the ability for a wheelchair user to negotiate effectively the interior and exterior, will be able to increase the maneuverability required in the presence of obstacles and provide a sufficient suspension to absorb the shock. The wheelchair user can attach and detach independently the power attachment.

Further work consists in the fact the product will be designed considering the chosen concept and detailed specifications and then tested in a real environment.

\section{References}

1. G. Quaglia, W. Franco, R. Oderio, IEEE International Conference on Robotics and Biomimetics (ROBIO), 800-805 (2009)

2. J.M. Lawn, T. Sakai, M. Kuroiwa, T. Ishimatsu, Journal of HWRS-ERC 2(2), 33-39 (2001)

3. J. Yuan, S. Hirose, Journal of Robotics and Mechatronics 17(1), 44-51 (2005)

4. S. Suryawanshi, K. Janardhan Reddy, International Journal of Research in Mechanical Engineering 1(2), 1-10 (2013)

5. K. Yoneda, Y. Ota, S. Hirose, Proceeding of 4th International Conference on Climbing and Walking Robots CLAWAR, 569-576 (2001)

6. J. Yuan, S. Hirose, Robotics and Biomimetics, IEEE International Conference on Robotics and Biomimetics (ROBIO), 654-659 (2004)

7. G.E. Dieter, Engineering Design, Fourth Edition (McGraw-Hill, 2007)

8. D. Ullman, The Mechanical Design Process, Fourth Edition (McGraw-Hill, 2007)

9. G. Pahl, W. Beitz, Engineering Design a Systematic Approach Second Edition (Springer Verlag, 1996)

10. K. Otto, K. Wood, Product Design Techniques in Reverse Engineering and New Product Development (Prentice Hall, 2001)

11. T.K. Ulrich, S.D. Eppinger, Product Design and Development, Fifth Edition (McGraw Hill, 2009)

12. S. Pugh, Total Design - Integrated Methods for Successful Product Engineering (Addison-Wesley, 2005)

13. A. Raman, Mechanical Engineering (Industrial Press Inc, 2007) 